\title{
The Diet Composition of Four Vesper Bats (Chiroptera: Vespertilionidae) from the Centre Region of Cameroon (Central Africa)
}

\author{
Mbeng Donatus Waghiiwimbom ${ }^{1, ~ *, ~ B a k w o-F i l s ~ E r i c ~ M o i s e ~}{ }^{1}$, Atagana Patrick Jules ${ }^{1}$, \\ Joseph Lebel Tamesse ${ }^{2}$
}

${ }^{1}$ Department of Biological Sciences, Faculty of Sciences, University of Maroua, Maroua, Cameroon

${ }^{2}$ Higher Teachers Training College, University of Yaounde I, Yaounde, Cameroon

\section{Email address:}

mbengdona@yahoo.com (M. D. Waghiiwimbom), filsbkw27@gmail.com (Bakwo-Fils E. M.), apatrickjules@yahoo.fr (A. P. Jules), jltamesse@yahoo.fr (J. L. Tamesse)

*Corresponding author

\section{To cite this article:}

Mbeng Donatus Waghiiwimbom, Bakwo Fils Eric-Moise, Atagana Patrick Jules, Joseph Lebel Tamesse. The Diet Composition of Four Vesper Bats (Chiroptera: Vespertilionidae) from the Centre Region of Cameroon (Central Africa). International Journal of Natural Resource Ecology and Management. Vol. 4, No. 6, 2019, pp. 153-163. doi: 10.11648/j.ijnrem.20190406.11

Received: August 3, 2019; Accepted: September 11, 2019; Published: October 9, 2019

\begin{abstract}
Diet is an important part of microbat biology that provides valuable information on how species interact and persist in an ecosystem. Dietary analysis is also important in interpreting their role as predator of night flying insects. Our objective is to report on the food and feeding habits of four microbats (Neoromicia nana, Neoromicia tenuipinnis, Pipistrellus nanulus and Scotoecus hirundo) in the Centre Region of Cameroon, based primarily on fecal remains collected from bats captured at their feeding and roosting sites. Bats were captured from January 2016 to December 2017 using mist nets and their fecal pellets were collected for dietary analysis. Dietary analysis of 393 fecal pellets of 51 vesper bats showed that bats consumed eight insect Orders (Coleoptera, Diptera, Lepidoptera, Hemiptera, Hymenoptera, Isopteran, Trichoptera and Neuroptera). Lepidoptera's $(\% \mathrm{v}=58.5 \%)$ were the most important food source for these bats. The three most frequent insect Orders encountered in the pellets of these bats were Lepidoptera $(\% \mathrm{f}=96.6 \%)$, dipteran $(\% \mathrm{f}=79.1 \%)$ and Coleoptera $(\% \mathrm{f}$ $=77.5 \%)$. We observed large amounts of Diptera content in the diet of $S$. hirundo $(\% \mathrm{v}=39.7 \%)$, . tenuipinnis $(\% \mathrm{v}=29.6 \%)$. Elucidating the role of bats in Dipteran control could lead to benefits for both the conservation of bats and public health. Equally erecting of bat houses to attract bats in farms so that they feed on insects could reduce or minimize the use of pesticides. A statistical analysis of mean percentage frequency and volume of food items indicated that among the four-bat species, consumed prey items were similar $(\mathrm{H}=0.2, \mathrm{p}=0.9)$. This new information can be used for both conservation and to improve public awareness about bats in Cameroon.
\end{abstract}

Keywords: Centre Region, Cameroon, Diet, Vesper Bats, Insects, Conservation

\section{Introduction}

Insectivorous bats make up about $70 \%$ of bat species worldwide [1]. Over the past years, many studies on their diet have produced enormous amount of data essential for the understanding of their foraging behavior and ecology $[2,3]$. Dietary analysis of microbats is important in interpreting their ecological role as predators on their respective preys $[4$, 5] as well as their potential to be used as biological control agents in both natural and modified (e.g. agricultural) areas
[6-8]. They feed on several major farm land insect pests such as corn earworm moths (a major pest of corn, beans and tomatoes), spotted cucumber beetles, brown stink bug, fruit flies, celery looper, green stink bug $[9,10]$. Thus, in terms of number of insects consumed, large colonies of insectivorous bats may consume millions of insects in farm lands each season [11]. For instance, a single colony of 150 big brown bats (Eptesicus fuscus), in Indiana consumes nearly 1.3 million pest insects each year, including a taxonomic richness of mosquitoes [11]. 
A decline in microbat bat diversity and abundance might increase our dependence on chemical pesticides that often cause more long-term problems than they solve [12]. In recent years, it was found that $75 \%$ of maize, cowpea, and millet samples from northern Cameroon contained pesticide residues above the maximum residue limits. High amounts of organophosphorous pesticide residues were also found in stored cowpea revealing a potential human dietary risk related to consumption of these grains [13]. Therefore, knowledge of insect prey provides valuable information for assessing the potential value of bats in controlling insect pests and thus reducing the dependence on toxic and dangerous pesticides especially in areas where urban and cultivated lands have replaced natural habitats in Cameroon.

Bats are particularly diverse in the tropics [14]. In Cameroon there are over 100 species of bats [15]. Despite this rich diversity, there is very little data on the feeding ecology and diet of insectivorous bats and this reflects a general paucity on ecological study of microchiropterans in Cameroon. It is therefore of interest to acquire information about the types of insects these bats feed on, because this can have major implications for the biological control of agricultural pest and disease vectors such as mosquitoes.

This study is focused on the diet of four types of insectivorous bats in the Centre region of Cameroon, based primarily on fecal remains collected from bats captured at their feeding and roosting sites. Dietary data is obtained from analysis of fecal samples collected at different seasons for two years (January 2016 to December 2017). According to literature $N$. nana has a weight of $3.6 \mathrm{~g}(\mathrm{n}=237)$, forages by slow-hawking in moderately uncluttered places. Diet consist mainly of small Coleoptera, Lepidoptera and to a lesser extent some Diptera [16-18]. Diet varies between individuals and seasons; small moths are eaten during cool, dry seasons, but on very few occasions during wet season [19]. An individual in the dry season in Zimbabwe $\left(18^{\circ} 10^{1} \mathrm{~S}: 28^{\circ} 13^{1} \mathrm{E}\right)$ had eaten $50 \%$ Coleoptera and 50\% Lepidoptera: in the same locality in the wet season, fecal pellet analysis revealed $52 \%$
Coleoptera, 40\% Lepidoptera and 8\% Diptera [16, 17]. Previous studies reveals that $N$. tenuipinnis has a weight of $4.4 \mathrm{~g},(\mathrm{n}=44)$ forages by slow to moderately fast-hawking in open spaces and spaces with background clutter [18]. There is no previous data on diet but based on body size; the species may probably consumes very small flying insects [18]. According to literature Pipistrellus nanulus has a weight of $4 \mathrm{~g}(\mathrm{n}=22)$ and two individuals were seen foraging at daybreak for insects swarming over a damp wallow [20]. Scotoecus hirundo has a weight of $10.2 \mathrm{~g}(\mathrm{n}=36)$, forages by moderately fast-hawking and there is no known published data on diet [18]. Specifically, our objective is to report on the food and feeding habits of the four insectivorous bats in the Centre Region of Cameroon. These data can serve as basic information for conservation measures.

\section{Materials and Methods}

\subsection{Study Area and Sampling Sites}

The study was conducted in the Centre region of Cameroon, situated in the South Cameroon plateau [21]. It is the second largest in the country with an area of $68,953 \mathrm{~km}^{2}$ and divided into ten administrative divisions and 71 subdivisions. The original vegetation was dominated by forest in the Southern part and savannah in the northern part [21]. Today, very little primary forest remains due to human activities such as logging, the establishment of plantations and urban expansion [22, 23].

The climate of the region is equatorial Guinean type, characterized by four unequal seasons that alternate throughout the year with two dry and two rainy seasons [24]. A long dry season from mid-November to mid-March, a short rainy season from mid-March to June, a short dry season from July to August and a long rainy season from September to mid-November [25]. The average annual temperature varies between 22 and $32^{\circ} \mathrm{C}$. Rainfall is between 1300 and $1500 \mathrm{~mm}$ per year [24].

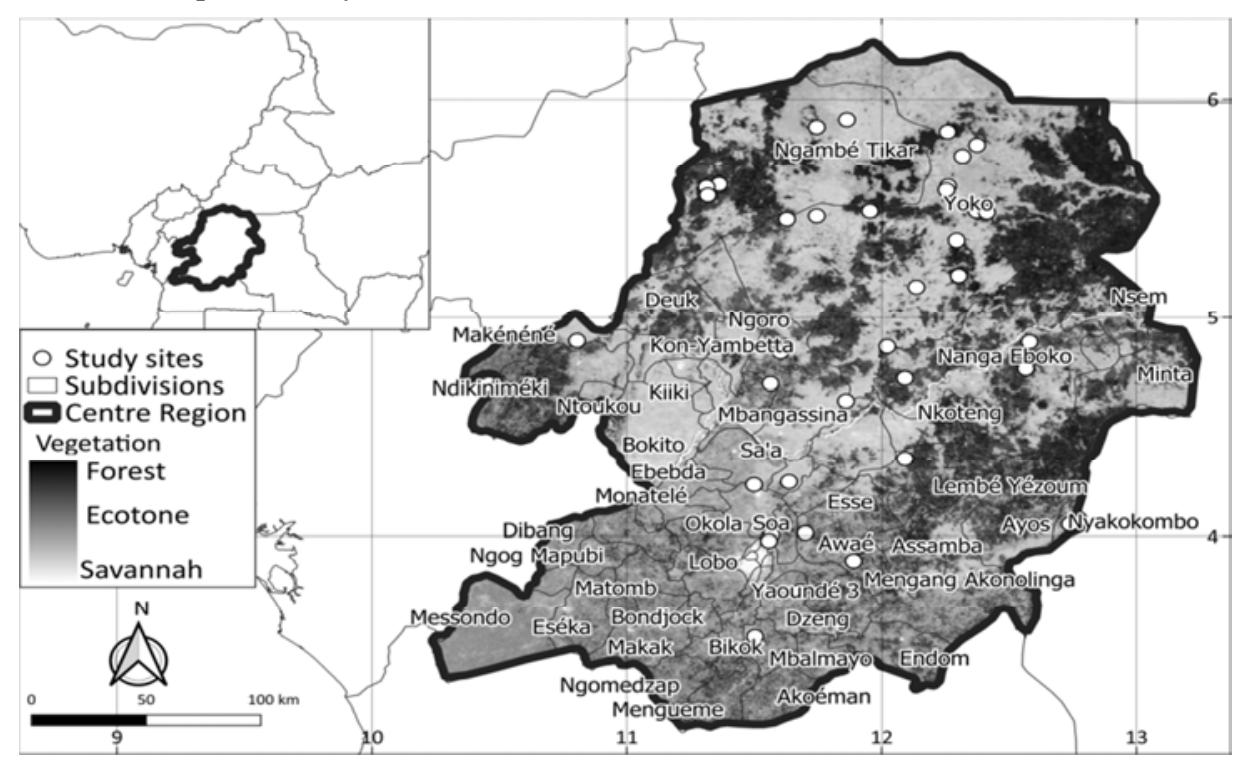

Figure 1. Map showing locations in which the survey was conducted. 


\subsection{Dietary Samples and Bat Capture}

Fecal samples were collected opportunistically from four microbat species (Neoromicia nana, Neoromicia tenuipinnis, Pipistrellus nanulus and Scotoecus hirundo) captured during bat surveys conducted from January 2016 to December 2017 (Table 2). The bats were captured monthly during five nonconsecutive nights using mist nets of 6-12 meters length with five shelves. We carried out captures within farms, savannah and forest. Forty-five sites were chosen for sampling (Figure 1). Morphological measurements were taken by following standard techniques of Bates and Harrison (1997). The geographical location of each site was recorded with a hand- held GPS (Garmin eTrex). Each night, at least two and up to nine mist nets were attached to 4 meter poles and stretched near roosting sites (around cave entrances, tree cavities etc.), foraging sites over water surfaces (e.g. streams, rivers, lakes, ponds, etc.), across cultivated farms, plantations, along forest edges or across forest roads for a total of six hours at each site between $6 \mathrm{pm}$ and 12 midnight (Table 1). They were checked at intervals of 15 minutes. Every captured microbat was put in an airy bag with a draw string for two hours in order to collect feces. They were then release in the place of capture after collection of feces.

Table 1. Main habitat types and geographic coordinates of sites recorded for vesper bats in the Centre Region of Cameroon form January 2016 to December 2017.

\begin{tabular}{|c|c|c|c|c|}
\hline Localities & Sites & Main Habitat & North & East \\
\hline Mbouckulu & Site1 & Farm (fish-pond) & $03^{\circ} 31^{\prime} 84.4^{\prime \prime}$ & $11^{\circ} 29^{\prime} 71.1^{\prime \prime}$ \\
\hline Ngousso & Site 2 & Farm & $03^{\circ} 54^{\prime} 28.4^{\prime \prime}$ & $11^{\circ} 33^{\prime} 02.8^{\prime \prime}$ \\
\hline Soa & Site 3 & Farm & $03^{\circ} 56^{\prime} 29.5^{\prime \prime}$ & $11^{\circ} 35^{\prime} 42.3^{\prime \prime}$ \\
\hline Mbandjock & Site 4 & Savanna/river & $04^{\circ} 45^{\prime} 05.7^{\prime \prime}$ & $11^{\circ} 91^{\prime} 17.6 "$ \\
\hline Nditam & Site 5 & Farm/river & $05^{\circ} 21^{\prime} 93.9^{\prime \prime}$ & $11^{\circ} 14^{\prime} 46.4^{\prime \prime}$ \\
\hline Nkolbisson & Site 6 & Farm/Lake & $03^{\circ} 87^{\prime} 61.2^{\prime \prime}$ & $11^{\circ} 42^{\prime} 57.6^{\prime \prime}$ \\
\hline Nkol-Biyem & Site 7 & Farm (pond) & $04^{\circ} 13^{\prime} 07.1^{\prime \prime}$ & $11^{\circ} 26^{\prime} 23.7^{\prime \prime}$ \\
\hline Ntui/farm & Site 8 & Farm & $04^{\circ} 81^{\prime} 41.1^{\prime \prime}$ & $11^{\circ} 34^{\prime} 64.3^{\prime \prime}$ \\
\hline Bangi-Yoko & Site 9 & Forest (stream) & $05^{\circ} 15^{\prime} 85.0^{\prime \prime}$ & $12^{\circ} 12^{\prime} 61.9^{\prime \prime}$ \\
\hline Makenene & Site 10 & Farm/stream & $04^{\circ} 52^{\prime} 96.2^{\prime \prime}$ & $10^{\circ} 47^{\prime} 77.3^{\prime \prime}$ \\
\hline Balamba & Site 11 & Savanna (near building) & $04^{\circ} 40^{\prime} 10.7^{\prime \prime}$ & $11^{\circ} 25^{\prime} 72.5^{\prime \prime}$ \\
\hline linte 1 & Site 12 & Farm/tree cavity & $05^{\circ} 37^{\prime} 84.6^{\prime \prime}$ & $11^{\circ} 67^{\prime} 51.2^{\prime \prime}$ \\
\hline Linte 2 & Site 13 & Forest/river & $05^{\circ} 29^{\prime} 66.8^{\prime \prime}$ & $11^{\circ} 66^{\prime} 39.6$ "' \\
\hline
\end{tabular}

\subsection{Data Collection}

Vesper fecal pellets were collected at eleven sites (Table 2). Some individual bats of $N$. nana and P. nanulus did not defecate and no fecal samples were collected. The fecal pellets of each individual microbat bat were kept in plastic vials with $70 \%$ alcohol to inhibit fungi growth for later analyses.

Table 2. Bat species recorded, sampling success, number of individuals with pellets and number of pellets analyzed.

\begin{tabular}{|c|c|c|c|c|c|c|}
\hline Taxon & Localities & Month & $\begin{array}{l}\text { Mist-net Length } \\
\text { M (m) }\end{array}$ & $\begin{array}{l}\text { Number of } \\
\text { nights }\end{array}$ & $\begin{array}{l}\text { Number of individuals } \\
\text { with pellets }\end{array}$ & $\begin{array}{l}\text { Total number of } \\
\text { pellets analysed }\end{array}$ \\
\hline Neoromicia nana & Mbockulu & March 2016 & 48 & 5 & 3 & 17 \\
\hline Neoromicia nana & Ngousso & May 2016 & 48 & 5 & 13 & 77 \\
\hline Neoromicia nana & Soa & August 2016 & 30 & 5 & 5 & 41 \\
\hline Neoromicia nana & Mbandjock & January 2017 & 48 & 5 & 2 & 13 \\
\hline Neoromicia nana & Nditam & June 2017 & 72 & 5 & 2 & 20 \\
\hline Neoromicia nana & Nkolbisson & July 2017 & 30 & 5 & 3 & 30 \\
\hline Neoromicia nana & Bangi-Yoko & September 2017 & 66 & 5 & 3 & 30 \\
\hline Neoromicia nana & Makenene & December 2017 & 48 & 5 & 2 & 20 \\
\hline Scotoecus hirundo & Ngousso & May 2016 & 48 & 5 & 1 & 5 \\
\hline Scotoecus hirundo & Balamba & August 2017 & 48 & 5 & 5 & 40 \\
\hline Pipistrellus nanulus & Ngousso & May 2016 & 48 & 5 & 1 & 10 \\
\hline Pipistrellus nanulus & Linte 1 & November 2016 & 48 & 5 & 9 & 80 \\
\hline \multirow[t]{2}{*}{ Neoromicia tenuipinnis } & Linte 2 & November 2017 & 48 & 5 & 2 & 10 \\
\hline & & Total & 534 & 50 & 51 & 393 \\
\hline
\end{tabular}




\subsection{Dietary Analyses}

Fecal analysis followed the method of Whitaker (1988). At least five pellets were randomly selected from each individual microbat for fecal analysis (Table 2). Each selected pellet was put in a Petri dish and soaked with one or two drops of water to soften it, and then teased apart with a dissecting needle and fine forceps. The fragments were observed under a microscope (at a magnification of 100X) and identified to Order or family level using insect keys [28-31]. Microphotographs were taken with a digital camera of mark Sony with 6X optical zoom, to confirm the insect parts identification. Percentage volume was estimated using sum of individual volume of food divided by total volume and expressed as percentage [27]. Frequency was calculated as number of pellet containing an item divided by total samples and expressed as percentage. The mean percentage volume and frequency was then calculated for each order for each bat. Differences in mean percentage frequency and volume of diets among bat species were examined using Kruskal Wallis H-test. Statistical analyses were performed using PAST 3.02a [32].

\section{Results}

Forty-eight individuals of $N$. nana (29 males and 19 females) were recorded at three sites (Ngousso-Yaounde, Nkolbisson-Yaounde and Soa-Ebogo) in cultivated farms with banana and plantain plants (Musa spp.) and over open drinking sites (Makenene stream, Nditam River, Mbockulu fish pond and Bangi-Yoko stream) (Table 1). At NgoussoYaounde where most of the individuals were recorded, they do not begin to forage until after $7 \mathrm{pm}$. N. nana was found to be using an uncompleted building as a night roost during nightly foraging bouts for rest and digestion of food beside the farm at Ngousso. Five individuals of Scotoecus hirundo (Three males and two females) were mist-nested near a building in the woody savannah at Balamba. An additional male individual was captured from a cultivated farm at Ngousso-Yaounde (Table 1). Two individuals of Neoromicia tenuipinnis were caught foraging over an opened river, along an opening in the forest at Linte (Table1). Thirteen individuals of $P$. nanulus (seven females and six males) were recorded at six sites with individuals caught at three sites in the savannah (Nkol-Biyem fish pond, Linte and Mbandjock), two sites in cultivated farms (Ngousso and Ntui) and a single site at the forest (Linte). At the savannah area of Linte, individuals were caught near a building (Table 1). Overall, 51 vesper bats ( 20 in the rainy season and 31 in the dry season) were captured from thirteen sites (Table 1) out of the fortyfive sites surveyed (Figure 1).

A total of 393 fecal pellets (129 in the rainy-season and 264 in the dry-season) were analyzed from the four species of microbats (Neoromicia nana, Neoromicia tenuipinnis, Scotoecus hirundo and Pipistrellus nanulus). Insect remains of eight insect Orders were identified in the fecal pellets of these bats (Coleoptera, Lepidoptera, Diptera, Hymenoptera, Hemiptera, Isoptera, Nauroptera and Trichoptera) (Table 3). The most frequent insect Orders identified in the pellets were Lepidoptera $(\% \mathrm{f}=96.6 .6 \%)$, followed by Diptera $(\% \mathrm{f}=$ $79.1 \%)$, then Coleoptera $(\% \mathrm{f}=77.5 \%)$ and Hymenoptera $(\% \mathrm{f}$ $=30.5 \%)$. The other insect Orders $(\%<21 \%)$ were uncommon (Table 3). A statistical analysis of mean percentage frequency and volume of food items indicated that among the four-bat species, consumed prey items were $\operatorname{similar}(\mathrm{H}=0.2, \mathrm{p}=0.9)$.

Table 3. Percentage Frequency $(\% f)$ and volume $(\% v \pm S E)$ of all insect orders in bat faeces from the studied species in the Centre region of Cameroon from January 2016 to December 2017.

\begin{tabular}{|c|c|c|c|c|c|c|c|c|c|}
\hline \multirow{2}{*}{$\begin{array}{l}\text { Food items } \\
\text { consumed }\end{array}$} & \multicolumn{2}{|c|}{ N. nana $(\mathrm{n}=33)$} & \multicolumn{2}{|c|}{ N. tenuipinnis $(\mathrm{n}=2)$} & \multicolumn{2}{|c|}{ P. nanulus $(\mathrm{n}=10)$} & \multicolumn{2}{|c|}{ S. hirundo $(\mathrm{n}=6)$} & \multirow{2}{*}{$\frac{\text { Mean }}{\% \text { f }}$} \\
\hline & $\% \mathrm{v} \pm \mathrm{SE}$ & $\%$ f & $\% \mathrm{v} \pm \mathrm{SE}$ & $\%$ f & $\% \mathrm{v} \pm \mathrm{SE}$ & $\%$ f & $\% \mathrm{v} \pm \mathrm{SE}$ & $\%$ f & \\
\hline Lepidoptera & $67.5 \pm 3.3$ & 91.2 & $57.9 \pm 3.9$ & 100 & $64 \pm 7.11$ & 100 & $44.4 \pm 5.8$ & 95 & 96.6 \\
\hline Coleoptera & $21.4 \pm 2.4$ & 72.6 & $7.4 \pm 0.8$ & 100 & $14.3 \pm 5.2$ & 67.7 & $13.5 \pm 4.1$ & 70.4 & 77.5 \\
\hline Diptera & $8.1 \pm 1.2$ & 44.4 & $29.6 \pm 5.9$ & 100 & $19.7 \pm 3.9$ & 73.6 & $39.7 \pm 9.2$ & 98.3 & 79.1 \\
\hline Hemiptera & $1.2 \pm 0.5$ & 7.3 & $2.7 \pm 0.5$ & 70 & $0.8 \pm 0.4$ & 5 & - & - & 20.6 \\
\hline Hymenoptera & $0.8 \pm 0.3$ & 10.6 & $2.4 \pm 0.3$ & 60 & $1.2 \pm 0.5$ & 25 & $2.3 \pm 1.5$ & 26.4 & 30.5 \\
\hline Isoptera & $0.9 \pm 0.8$ & 1.8 & & & - & - & & - & 0.5 \\
\hline Nauroptera & & - & - & - & - & - & $1.4 \pm 1.4$ & 3.3 & 0.8 \\
\hline Trichoptera & $0.1 \pm 0.1$ & 0.9 & & & - & - & $0.2 \pm 0.2$ & 3.3 & 0.2 \\
\hline
\end{tabular}

\subsection{Diet Composition of Neoromicia nana $(n=33)$}

The highest numbers of insect Orders (seven) were identified in the 248 fecal samples of N. nana. This is more diverse than previously recorded (e.g. 3 in Fenton and Thomas, 1980; 4 in Fenton et al., 1977). Over half $(67.5 \% \pm$ $3.3 \mathrm{SE})$ of the mean percentage volume consisted of Lepidoptera. Scales and filiform antenna of moths were very conspicuous in the diet of this species (Figure 2). The diet was also dominated by Coleoptera $(\% \mathrm{v}=21.4 \% \% \pm 2.4 \mathrm{SE})$ and Diptera $(\% \mathrm{v}=8.1 \pm 1.2 \mathrm{SE})$. Coleopterans were beetles (Elateridae), particularly antenna of click beetles (Figure 2). Lepidopterans were the most frequently consumed food item (91.2\%), followed by Coleopterans (72.6\%), Dipterans (44.4\%), and Hymenopterans (10.6\%) respectively (Figure $2)$. The other remaining taxa $(\% \mathrm{v}<2 \% ; \%$ f $<8 \%)$ were occasionally consumed by bats. 

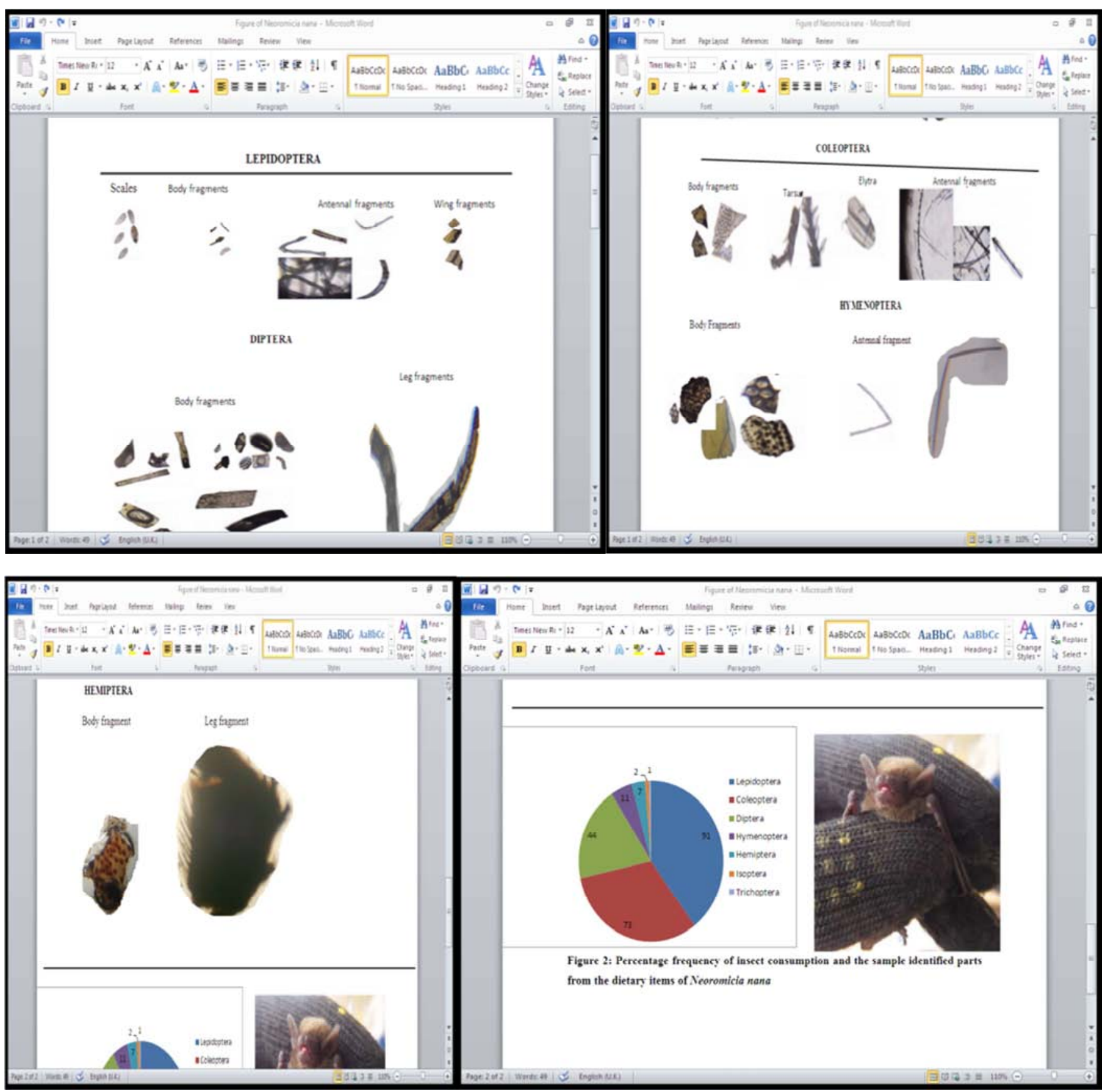

Figure 2. Percentage frequency of insect consumption and the sample identified parts from the dietary items of Neoromicia nana.

Seasonal diet changes

In January, March and from May to September and December, the mean volume of insect orders found in the diet of $N$. nana consisted mainly of Lepidoptera, Coleoptera and Diptera. In late March and May they became more diversified on their feeding habits as they fed on moths, beetles including few scarab (Scarabaeidae) and ground beetles (Carabidae) and more click beetles (Elateridae), negro bug (Cynidae), Dipterans, Hymenopterans, Isopterans and Trichopterans (Table 4).
The mean percentage volume of insect orders varies between individuals and months but not in a significant manner $(\mathrm{H}=0.5, \mathrm{P}=0.9)$. The frequency of insect orders found in the diet of $N$. nana show that they often select prey from Lepidoptera, Coleoptera and Diptera. Hymenopterans, Hemipterans, Trichopterans and Isopterans were sometimes selected. The seven insect orders were selected in the diet of this species in May 2016 (Table 4). 
Table 4. Percentage Frequency $(\% f)$ and volume $(\% v \pm S E)$ of all insect orders in bat feces from Neoromicia nana in the Centre region of Cameroon from January 2016 to December 2017.

\begin{tabular}{llllllll}
\hline \multirow{2}{*}{ Site } & Month & Lepidoptera & \multicolumn{2}{l}{ Coleoptera } & \multicolumn{2}{l}{ Diptera } \\
\cline { 3 - 7 } & & $\mathbf{\% v}$ & $\mathbf{\% f}$ & $\mathbf{\% v}$ & $\mathbf{\% f}$ & \%v & \%f \\
\hline Mbockulu n=3 & March 2016 & $62.6 \pm 2.4$ & 100 & $23.7 \pm 3.9$ & 95.3 & $10.1 \pm 0.5$ & 45.7 \\
Ngousso n=13 & May 2016 & $73.4 \pm 5.3$ & 91.5 & $18.1 \pm 3.9$ & 63 & $6.3 \pm 1.1$ & 51.4 \\
Soa n=4 & August 2016 & $69.1 . \pm 9.2$ & 90 & $22.7 \pm 6.6$ & 80 & $8.0 \pm 3.1$ & 49.5 \\
Mbandjock n=2 & January 2017 & $64.8 \pm 1.8$ & 100 & $22.9 \pm 1.6$ & 59.7 & $10.6 \pm 1.8$ & 61.9 \\
Nditam n=2 & June 2017 & $68.6 \pm 11$ & 100 & $15.3 \pm 5.8$ & 45 & $4.5 \pm 2.0$ & 35 \\
Nkolbisson n=3 & July 2017 & $75.7 \pm 9.9$ & 100 & $13.3 \pm 5.8$ & 75.7 & 100 & 13.3 \\
Bangi-Yoko n=3 & Early Sep 2017 & $48.7 \pm 14.6$ & 76.7 & $26.3 \pm 1.7$ & 96.7 & $16.9 \pm 11.6$ & $11.0 \pm 7.6$ \\
Makenene n=2 & Dec 2017 & $49.9 \pm 23.4$ & 70 & $33.7 \pm 25.6$ & 95 & 30 \\
\hline
\end{tabular}

Table 4. Continued

\begin{tabular}{|c|c|c|c|c|c|c|c|c|c|}
\hline \multirow{2}{*}{ Site } & \multirow{2}{*}{ Month } & \multicolumn{2}{|l|}{ Hemiptera } & \multicolumn{2}{|c|}{ Hymenoptera } & \multicolumn{2}{|l|}{ Isoptera } & \multicolumn{2}{|c|}{ Trichoptera } \\
\hline & & $\% v$ & $\%$ f & $\% v$ & $\%$ f & $\% v$ & $\%$ f & $\% v$ & $\%$ f \\
\hline Mbockulu $n=3$ & March 2016 & $0.5 \pm 0.5$ & 13.3 & $1.9 \pm 0.9$ & 29.6 & - & - & $0.4 \pm 0.4$ & 6.7 \\
\hline Ngousso $n=13$ & May 2016 & $0.6 \pm 0.3$ & 4.6 & $1.1 \pm 0.9$ & 10.9 & $2.2 \pm 1.9$ & 4.6 & 0.3 & 0.83 \\
\hline Soa $n=4$ & August 2016 & $0.2 \pm 0.2$ & 2 & - & - & - & - & - & - \\
\hline Mbandjock $n=2$ & January 2017 & - & - & $1.3 \pm 1.3$ & 14.5 & - & - & - & - \\
\hline Nditam $n=2$ & June 2017 & 20 & $1.1 \pm 0.3$ & 15 & - & - & - & - & \\
\hline Nkolbisson $\mathrm{n}=3$ & July 2017 & $75.7 \pm 9.9$ & 100 & $13.3 \pm 5.8$ & $75.7 \pm 9.9$ & - & - & - & - \\
\hline Bangi-Yoko $n=3$ & Early Sep 2017 & $5.0 \pm 4.8$ & 16.7 & - & - & - & - & - & - \\
\hline Makenene $n=2$ & Dec 2017 & - & - & - & - & - & - & - & - \\
\hline
\end{tabular}

\subsection{Diet Composition of Neoromicia tenuipinnis $(n=2)$}

The 10 fecal pellets collected in the forest from two individuals of $N$. tenuipinnis consisted almost entirely of Lepidoptera $(\% \mathrm{v}=57.9 \% \pm 3.9 \mathrm{SE} ; \% \mathrm{f}=100 \%)$ and Diptera $(\% \mathrm{v}=29.6 \% \pm 5.9 \mathrm{SE} ; \% \mathrm{f}=100 \%)$. Coleoptera $(\% \mathrm{v}=7.4 \% \pm 0.8 \mathrm{SE} ; \% \mathrm{f}=100 \%)$, Hemiptera $(\% \mathrm{v}=2.7 \%$ $\pm 0.5 \mathrm{SE} ; \% \mathrm{f}=70 \%)$ and Hymenoptera $(\% \mathrm{v}=2.4 \% \pm 0.3$ $\mathrm{SE} ; \% \mathrm{f}=60 \%$ ) (Table 3 ) were sometimes consumed by these bats. Antennal fragments, scales of moths and body fragments of Dipterans were the most frequently and dominated food item in all fecal samples examined (Figure 3).

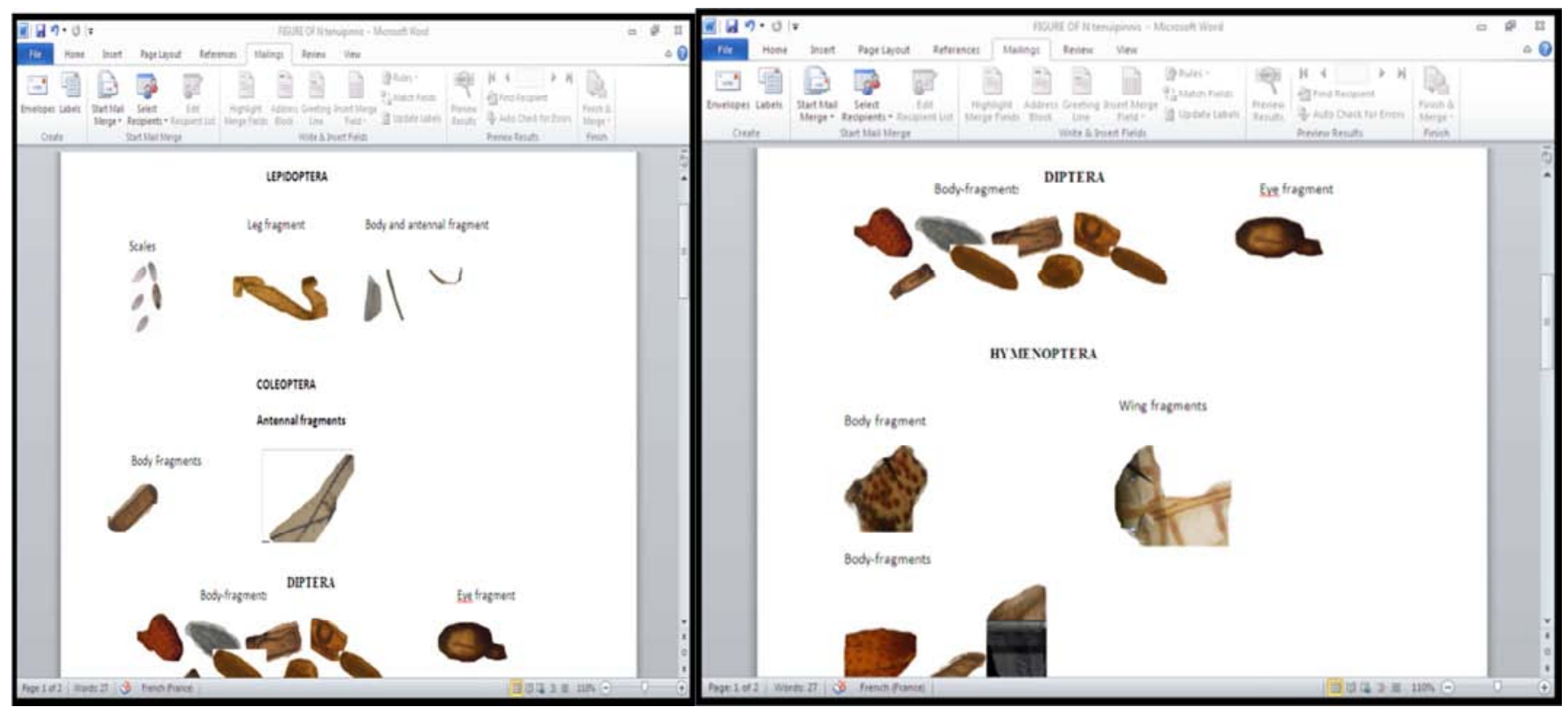




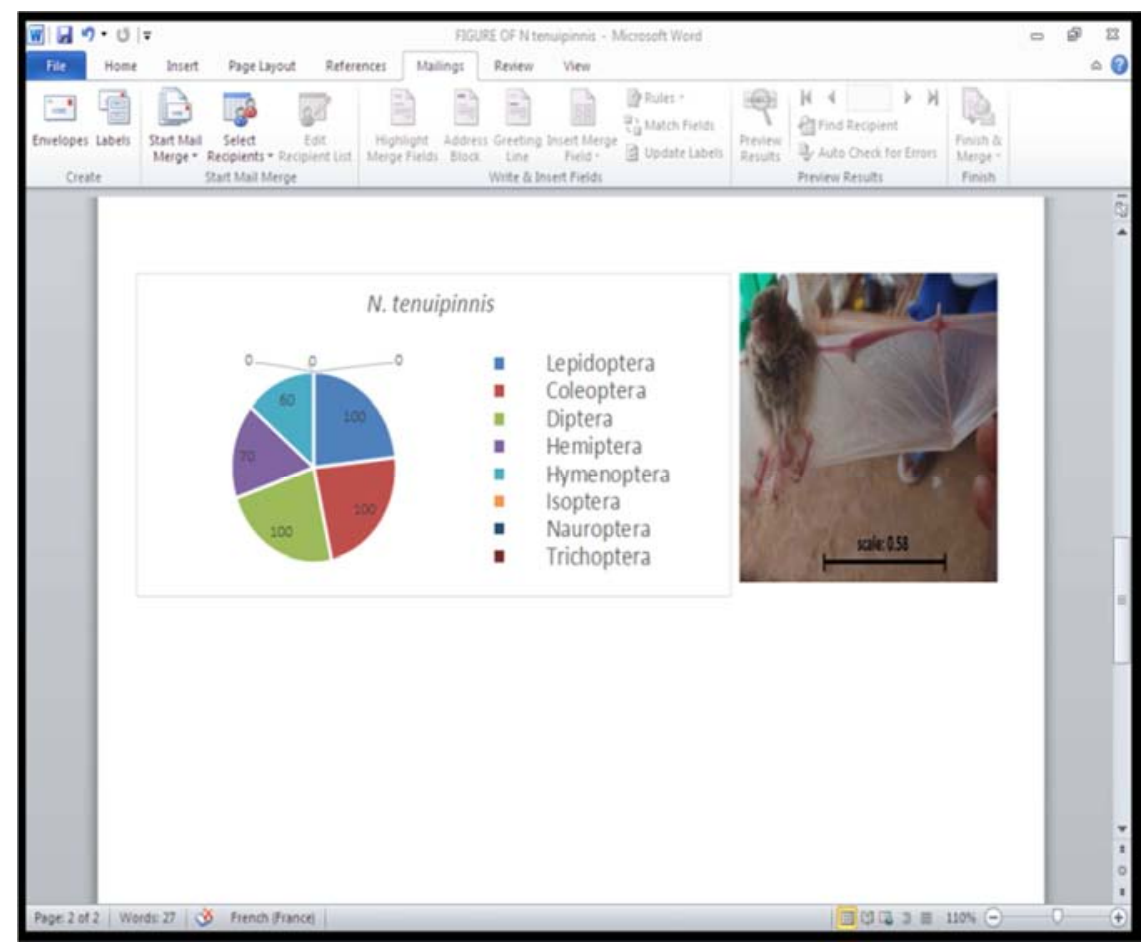

Figure 3. Percentage frequency of insect consumption and the sample identified parts from the dietary items of Neoromicia tenuipinnis.

\subsection{Diet Composition of Pipistrellus nanulus $(n=10)$}

Insect Orders frequently identified in the 90 analyzed fecal samples of $P$. nanulus included Lepidoptera $(\% \mathrm{v}=64 \% \pm 7.1$ SE; $\% \mathrm{f}=100 \%)$, Diptera $(\% \mathrm{v}=19.7 \% \pm 3.9 \mathrm{SE} ; \% \mathrm{f}=$ $73.6 \%)$ and Coleoptera $(\% \mathrm{v}=14.3 \% \pm 5.2 \mathrm{SE} ; \% \mathrm{f}=67.1 \%)$. Hemiptera $(\% \mathrm{v}=0.8 \% \pm 0.4 ; \% \mathrm{f}=5 \%)$ and Hymenoptera $(\% \mathrm{v}=1.2 \% \pm 0.5 ; \% \mathrm{f}=25 \%$ (Table 3$)$ were also identified
The insect orders identified in the fecal samples of the individual of this species captured at Ngousso (May 2016) included Lepidoptera $(\% \mathrm{v}=90.1 ; \% \mathrm{f}=100 \%)$, Diptera $(\% \mathrm{v}$ $=2.9 \% ; \% \mathrm{f}=100 \%)$, Hymenoptera $(\% \mathrm{v}=2.9 \% ; \% \mathrm{f}=50 \%)$, Hemiptera $(\% \mathrm{v}=2.6 \%, \% \mathrm{f}=10 \%)$. Scales, antennal fragments of moths and body fragments of Diptera were very conspicuous in the diet of this species (Figure 4).

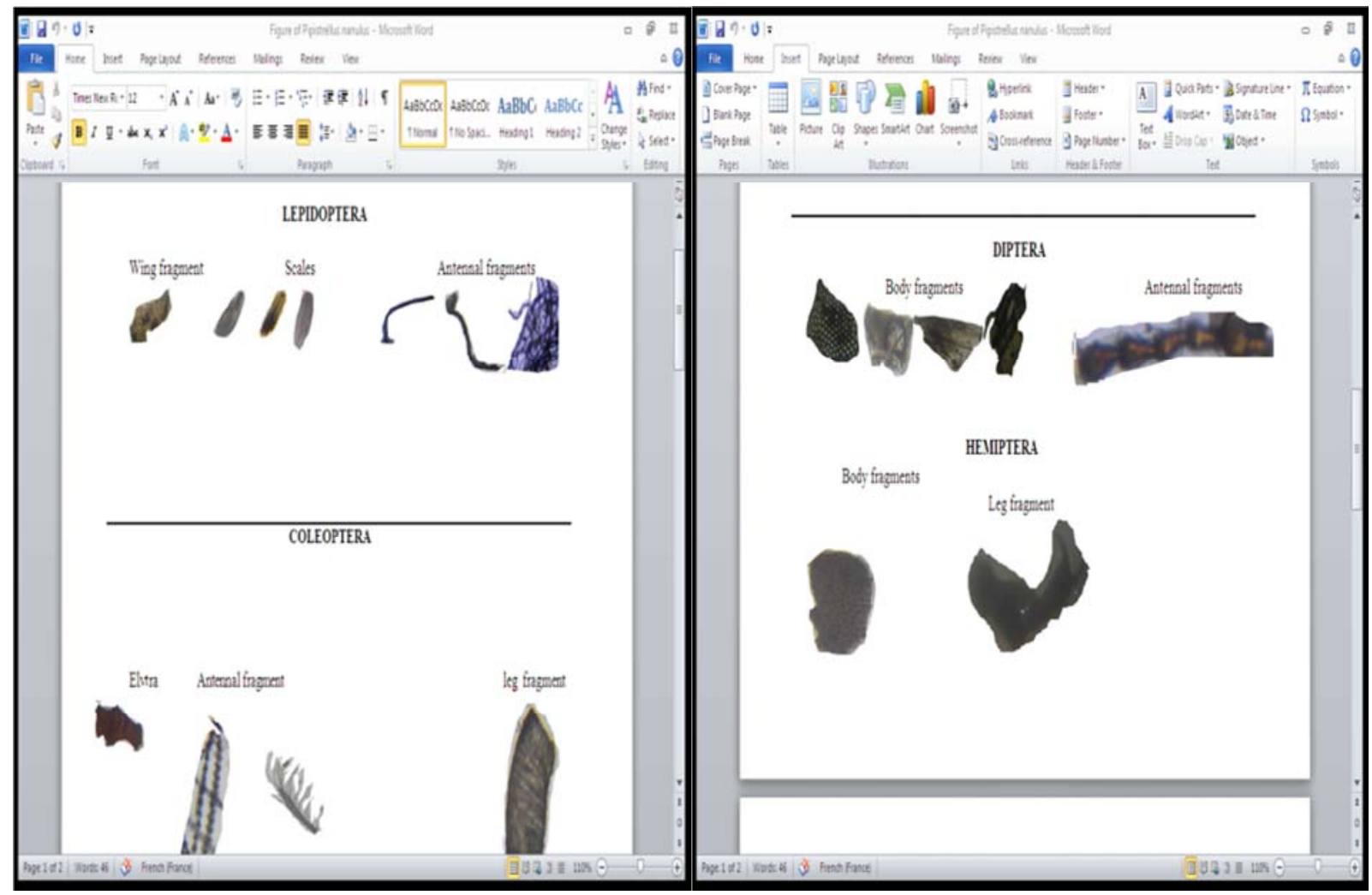




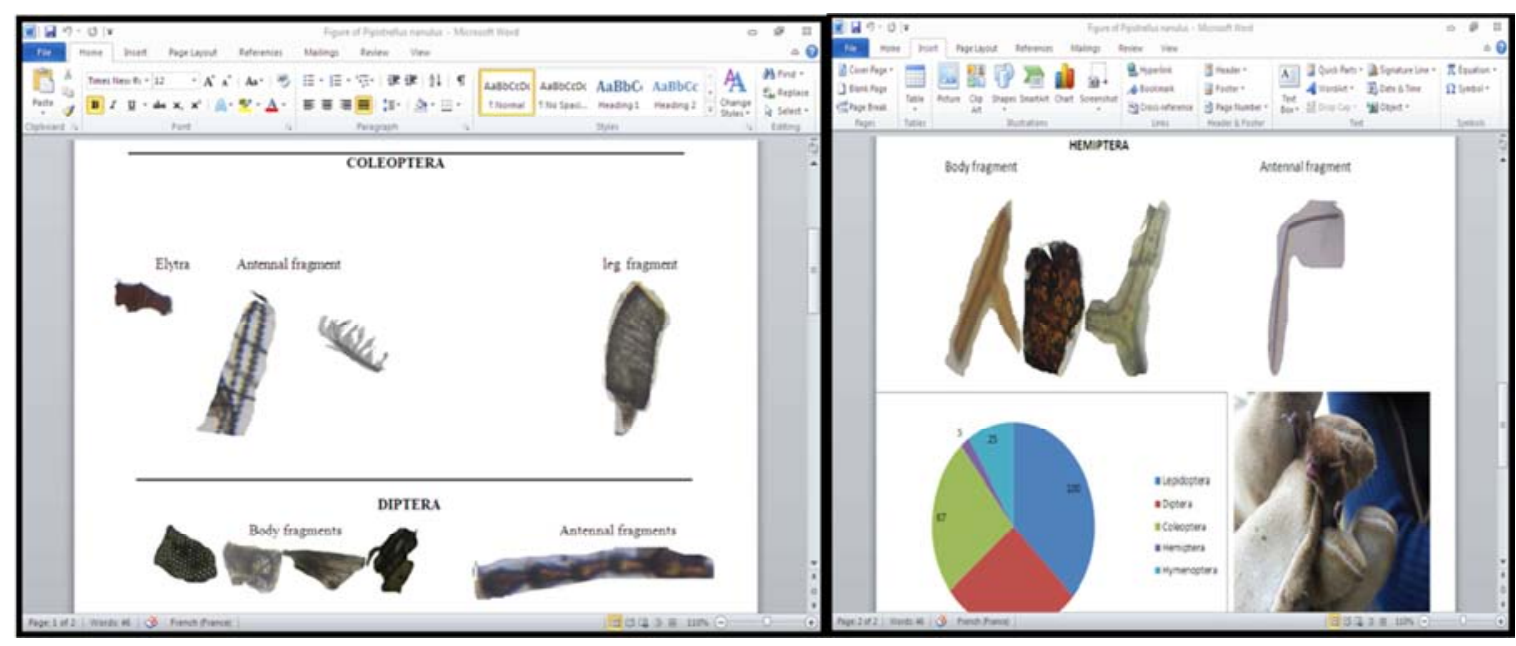

Figure 4. Percentage frequency of insect consumption and the sample identified parts from the dietary items of Pipistrellus nanulus.

\subsection{Diet Composition of Scotoecus hirundo $(n=6)$}

The 45 fecal pellets analyzed for this species contained the highest percentage content of Lepidoptera $(\% \mathrm{v}=44.1 \% \pm$ $5.8 \mathrm{~S} \mathrm{E})$ as well as a higher percentage content of Diptera $(\% \mathrm{v}$ $=39.7 \%)$ and Coleoptera $(\% \mathrm{v}=13.5 \pm 4.1 \mathrm{SE})$. Diptera (98.3\%), Lepidoptera (95\%), Coleoptera (70.4\%) and Hymenoptera (26.4\%) occurred more frequently in the diet of this species (Figure 5). Nauroptera and Trichoptera were occasionally consumed by bats (Table 3 ). The insect orders identified in the fecal samples of the individual of this species captured in a cultivated farm at Ngousso included Diptera $(\% \mathrm{v}=71.6 ; \% \mathrm{f}=100 \%)$, Lepidoptera $(\% \mathrm{v}=$ 22.4; $\% \mathrm{f}=100 \%)$, Hymenoptera $(\% \mathrm{v}=2.6 ; \% \mathrm{f}=60 \%)$, Trichoptera ( $\%$ v $1.2 \% ; \% \mathrm{f}=20 \%)$, and Nauroptera $(\% \mathrm{v}=$ $1.4 \%, \% \mathrm{f}=20 \%)$ and Coleoptera $(\% \mathrm{v}=0.8 \%, \% \mathrm{f}=20 \%)$. Trichoptera and Nauroptera were identified only in this individual.
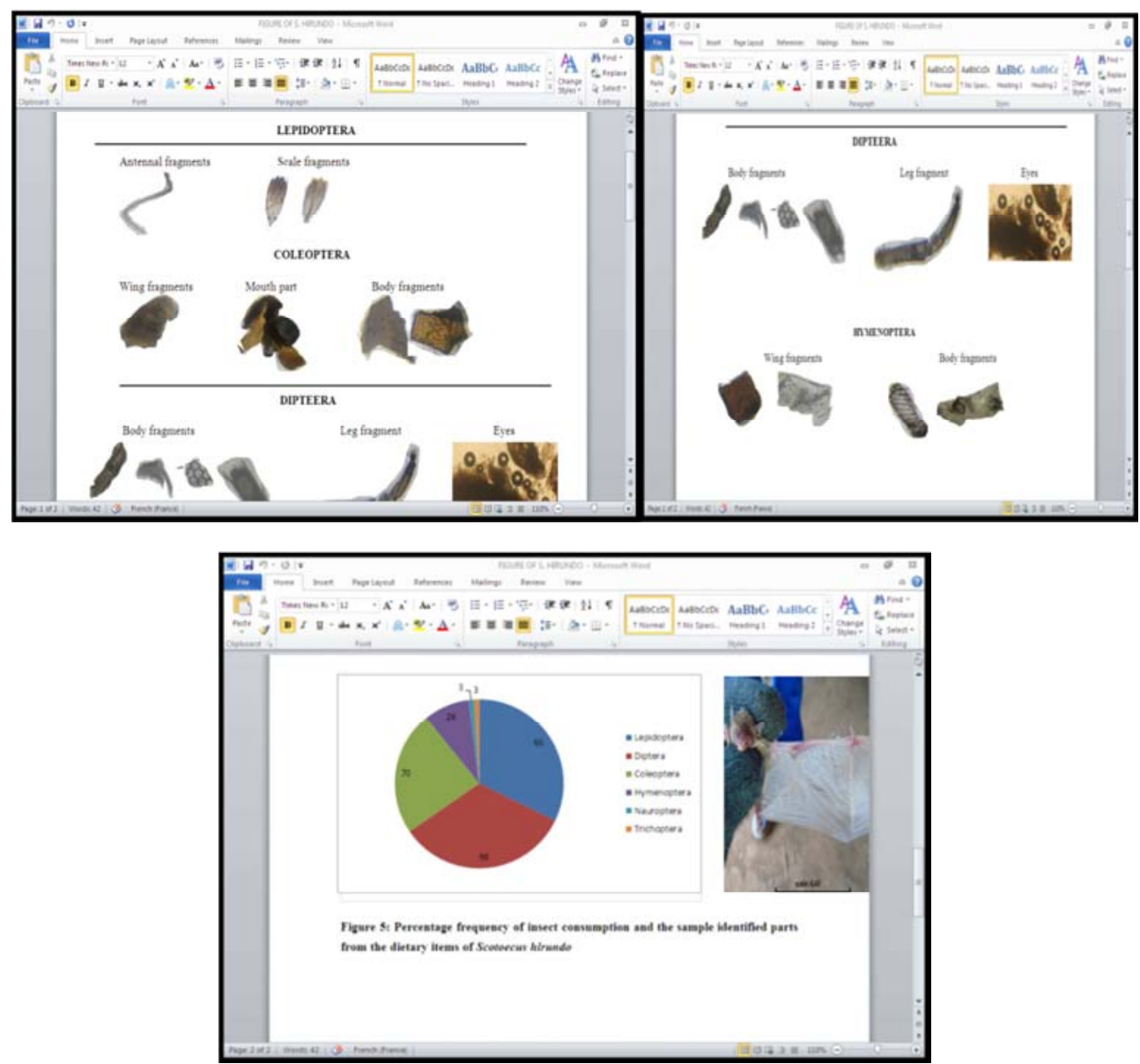

Figure 5. Percentage frequency of insect consumption and the sample identified parts from the dietary items of Scotoecus hirundo. 


\section{Discussion}

Our analysis gives some important baseline information about four microbat species from the Centre region of Cameroon. These bats fed mainly on Lepidoptera, Coleoptera and Diptera. Lepidoptera and Coleoptera were also important food items of most African insectivorous bats [33]. They are easily consumed by bats because they are rather large and produce more noise, thus are easily detectable [34]. Besides, Coleopterans are the largest insect order in the world comprising about one third of all insect species [35]. Also, our results are consistent with previous findings that bats that fed mainly on Diptera and Lepidoptera are often small and have high frequencies call $[36,37]$. Furthermore, the diet of insectivorous bats can vary among individual bat species, seasons, and food availability [38, 39]. The diets are discussed per species in the following paragraph.

In our study, the diet of $N$. nana contained seven insect Orders: Lepidoptera, Coleoptera, Diptera, Hymenoptera, Hemiptera, Isoptera and Trichoptera. Our results are consistent with the findings by Fenton and Thomas (1980) who found out that N. nana in Malawi feeds on Coleoptera and Lepidoptera, with some Diptera. Naidoo et al. 2011 in South Africa identified Lepidoptera, Coleoptera, Hemiptera, Diptera and Trichoptera in the diet of this species during late summer (April 2008) and in winter (June 2008) it fed on Lepidoptera, Coleoptera, Diptera, Hemiptera Trichoptera and Hymenoptera. In addition, several studies reported that bats of the genus Neoromicia consumed various food items. For instance, feces of Neoromicia capensis in Zimbabwe contained Coleoptera, Lepidoptera, Diptera, Hemiptera and Trichoptera [16, 17]. Furthermore, diet of Neoromicia zuluensis includes Lepidoptera and Coleoptera [41, 42]. These data might suggest that bats of the genus Neoromicia may likely feed selectively on different insect Orders according to predictions from optimal foraging theory where prey is ranked by the predator according to their profitability [43]. They may likely concentrate on the Orders of Lepidoptera, Coleoptera, Diptera and Hemiptera.

The monthly insect consumption rate of $N$. nana shows that there is little variation in the dietary consumption rate between individuals and seasons $(\mathrm{H}=0.5, \mathrm{P}=0.9)$. The food availability is higher during the period of the short rainy season (March 2016, May 2016 and June 2017), followed by short dry season (August 2016 and July 2017), long dry season (January 2017) and long rainy season (September 2017 and December 2017) (Table 4). The consumption of the most dominant components (Lepidoptera, Coleoptera and Diptera) shows that there is availability of these food items in the rainy and dry seasons. The high consumption of moths during the cool short dry season (August 2016 and July 2017) is consistent with the work of Happold and Happold (1996) who said small moths are eaten during the cool dry season. The diversified form of food selection confirms the banana bat ( $N$. nana) ability to consume different food items in different seasons according to availability and profitability
[44-46, 40].

Neoromicia tenuipinnis consumed five insect Orders in the forest namely Coleoptera, Lepidoptera, and Diptera, Hemiptera and Hymenoptera. There is no previous data on diet of $N$. tenuipinnis. Five insect orders were found in the diet of two individuals of $N$. tenuipinnis and the data on the number of insect orders may likely increase if the sample size is increased. This data may probably imply $N$. tenuipinnis just like bats of the genus Neoromicia consume a variety of insects but concentrate on the orders Lepidoptera, Diptera, and Coleoptera.

$P$. nanulus consumed five insect orders in this study comprising Lepidoptera, Diptera Coleoptera, Hemiptera and Hymenoptera. There is no previous data on diet of $P$. nanulus. However, many studies showed that bats in genus Pipistrellus fed on various food groups. For example, Feldman et al. (2000) reported that in Israel, Pipistrellus kuhlii consumed insects of the orders Lepidoptera, Coleoptera, Diptera, Hemiptera, Hymenoptera, Homoptera, and Nauroptera. Also, Pipistrellus pipistrellus in Switzerland and Britain feeds on small insects, mainly Diptera, Lepidoptera and Hemiptera [45, 48]. Moreover, Bartonička et al. (2008) found that Pipistrellus pygmaeus in a floodplain forest at the confluence of the Dyje and Morava Rivers (S Moravia, Czech Republic) fed on 40 taxonomic groups of invertebrates. Small Dipterans were the main food items. Surprisingly, a relatively high percentage of Brachycera was recorded. Furthermore, frequent prey items belonged to the orders Trichoptera, Hymenoptera, Coleoptera and Stenorrhyncha. The difference in feeding habits is probably due to energy needs of $P$. nanulus and the temporal availability of these insects. These data indicate that bats in genus Pipistrellus are opportunistic and generalist feeders.

The most heavily consumed food items of Scotoecus hirundo in our study were Lepidopterans and Dipterans with some Coleopterans. They also fed on Hymenopterans, Nauropterans and Trichopterans. Diet of $S$. hirundo $(\mathrm{n}=5)$ in August 2016 was composed of four insect orders (Lepidoptera, Coleoptera, Diptera and Hymenoptera) at Balamba. Thus there is variation in the diet of this species from the two different locations. This is consistent with previous findings that there is an often variation in diet of bats of the same species coming from different regions [50] and it is also dependent on season [51, 52]. The diet of the same species $(n=1)$ at Ngousso in May 2016 was made up of six insect orders (Lepidoptera, Coleoptera, Diptera, Hymenoptera, Nauroptera and Trichoptera). There is no previous data on diet of $S$ hirundo. However, studies showed that bats in the genus Scotoecus fed on various food items. For example, Monadjem (2010) reported that the diet of Scotoecus albofuscus consist of mainly Hemiptera but also includes Diptera and Coleoptera.

\section{Conclusion}

Our study gives some insights in the diets of four bat 
species from the Centre region of Cameroon. The diets of these species have never been studied anywhere in Cameroon before, hence this study provides important baseline information about these species. This new information can be used for both conservation and to improve public awareness about bats in Cameroon. Lepidopterans were an important food source for vesper bats in our study area and further investigations are now required into the quantity and composition of invertebrates consumed by microchiropterans in order to assess their economic and ecological role in the Centre region of Cameroon. We observed large amounts of Diptera content in the diet of $S$. hirundo, and it is possible it could play a role in the control of certain insect vector such as mosquitoes. Elucidating the role of bats in mosquito vector control could possibly lead to benefits for both the conservation of bats and public health. Equally, the bat diet could help reduce dependence on toxic and dangerous pesticides especially in agriculture. This could be done through the erecting of bat houses to attract bats in farms such that these bats can feed on such pests and thus reduce or minimize the use of pesticides. Conservation effort for the studied species should focus on their foraging and/or roosting areas.

\section{Acknowledgements}

We would like to thank Manforthang Ervis and Aaron Manga for field-work and logistic assistance. We also thank the Ministry for Scientific Research and Innovation in Cameroon for providing the research permit to capture bat species in the study area. Fieldwork materials were provided by IDEA WILD.

\section{References}

[1] Simmons, N. B. (2005). Order Chiroptera. pp. 312-529. In: D. E. Wilson, D. M. Reeder (eds.) Mammal Species of the World: A Taxonomic and Geographical Reference. Johns Hopkins University Press, Baltimore.

[2] Srilopan, S., Jantarit, S., \& Bumrungsri, S. (2018). The wrinkle-lipped free-tailed bat (Chaerephon plicatus Buchannan, 1800) feeds mainly on brown plant hoppers in rice fields of central Thailand. Acta Chiropterologica, 20: 207-220.

[3] Weterings, R., Wardenaar, J., S. Dunnz, S., \& Umponstira. C. (2015). Dietary analysis of five insectivorous bat species from Kamphaeng Phet, Thailand. Raffles Bulletin of Zool-ogy, 63: 91-96.

[4] Jedlicka, J. A., AND R, A. T. E. Vo., Almeida, P., 2016. Molecular scatology and high throughput sequencing reveal predominately herbivorous insects in the diets of adult and nestling Western Bluebirds (Sialia mexicana) in California vineyards. The Auk 134: 116-127.

[5] Krauel, J. J., V. Brown, V. A., Westbrook, J. K., \& Mccracken, G. F. (2018). Predator-prey interaction reveals local effects of high altitude - insect migration. Oecologia 186: 49-58.
[6] Kemp J., López-Baucellsa, A., Rocha, R., Owen S. Wangensteene, O. S., Andriatafikac, ZO., Nairc, A., Cabeza, M. (2019). Bats as potential suppressors of multiple agricultural pests: A case study from Madagascar. Agriculture, Ecosystems and Environment 269 88-96.

[7] Russo, D., Bosso, L. (2018). Novel perspectives on bat insectivory highlight the value of this ecosystem service in farmland: Research frontiers and management implications. Agriculture, Ecosystems \& Environment. Volume 266, Pages 31-38. https://doi.org/10.1016/j.agee.2018.07.024.

[8] Weier, S. M., Moodley, Y., Fraser, M. F., Lindena, V. M. G., Grass, I., Tscharntked, T., Peter J. Taylor, P. J. (2018). Insect pest consumption by bats in macadamia orchards established by molecular diet analyses.

[9] Maine J. J., \& Boyles, J. G. (2015). Bats initiate vital agroecological interactions in corn. Proc Natl Acad Sci U S A; 112 (40); 12438-12443; Vol. 112 no. 40.

[10] Maslo, B., \& Kerwin, k. (2017). Ecological and Economic Importance of Bats in integrated pest Management.

[11] Whitaker, J. O., Jr., 1995. Food of the big brown bat, Eptesicus fuscus, from maternity colonies in Indiana and Illinois. American Midland Naturalist, 134: 346-360.

[12] Zinn, T. L., \& Humphrey, S. R., 1981. Seasonal food resources and prey selection of the southeastern brown bat (Myotis austroriparius) in Florida. Florida Scientist, 44 (2); 81-90.

[13] Galani, J. H., Houbraken, M., Wumbei, A., Djeugap, J. P., Fotio, D., \& Spanoghe, P., 2018. Evaluation of 99 Pesticide Residues in Major Agricultural Products from the Western Highlands Zone of Cameroon using QuECHERS Method Extraction and LC-MS/MS and GC-ECD Analyses. Foods, 7184; doi: 10,3390/foods/7110184; w.w.w.mdi.com/journal/food.

[14] Willig, M. R., 2001. Latitude, common trends within. In 'Encyclopedia of Biodiversity'. (Ed. S. A. Levin.) pp. 701714. (Academic Press: San Diego.).

[15] 'ACR., 2018. African Chiroptera Report 2018. AfricanBats NPC, Pretoria. i-xvi + 1-8028 pp.

[16] Fenton, M. B., Boyle, N. G. H., Harrison, T. M., \& Oxley, D. J., 1977. Activity patterns, habitat use and prey selection by some African insectivorous bats. Biotropia 9: 73-85.

[17] Fenton, M. B., \& Thomas, D. W., 1980. Dry-season overlap in the activity patterns, habitat use and prey selection by sympatric African insectivorous bats. Biotropia 9: 73-85.

[18] Happold, M., \& Happold, D. C. D., 2013. Mammals of Africa Volume IV: Hedgehogs, shrews and bats. Blooms -bury Publishing, London, 800 p.

[19] Happold, D. C. D., \& Happold, M. (1996). Reproductive strategies of bats in Africa. Journal of Zoology (London) 222: 557-583.

[20] Lang, H., \& Chapin, J. P., 1917. Part 11. Notes on the distribution and ecology of Central African Chiroptera. Pp. 496-563 in The American Museum Congo expedition collection of bats (J. A. Allen. H. Lang and J. P. Chapin. eds). American museum of natural History Bulletin. 
[21] Zogning Moffo, M. O., Tsalefac, M., \& Iatu, O., 2011. FLOOD RISKS in the Mfoundi upstream drainage basin in Yaounde: A response to climatic modifications or to human impacts? PRESENT ENVIRONMENT AND SUSTAINABLE DEVELOPMENT, 5 (2); 33-44.

[22] Apiapuh, G. E., 2014. Cameroon Regional Geography and Geographical Skills and Techniques. Printed in Bamenda, Cameroon. 326p.

[23] Njabe, R. N., \& Akwanga, D., 2014. The New Human and Economic Geography for Cameroon. Sunway publishers, Limbé. G. C. E. Ordinary Level 200p.

[24] Madountsap, T. N., Zapfack, L., Chimi, D. C., Kabelon, B. L., Tsopmejio, T. I., Forbi, P. F., Ntonmen, Y. A., \& Ngasang, J. M., 2017. Biodiversity and Carbon Stock in the SODECAOAgro-forestry System of Center Region of Cameroon: Case of Talba Locality American Journal of Agriculture and Forestry; $5(4) ; 121-129$.

[25] Santoir, C., \& BOPDA, A., 1995. Atlas régional SudCameroun. Office de la Recherche Scientifique et Technique Outre-mer, Paris, $53 \mathrm{p}$.

[26] Bates, P. J. J and Harrison, D. L., 1997. Bats of the Indian subcontinent. Harrison Zool. Mus. Pub., England.

[27] Whitaker, J. O. Jr., 1988. Food habits analysis of insectivorous bats. Pp. 171-189 in Ecological and behavioral methods for the study of bats (T. H. Kunz, ed.). Smithsonian Institution Press, Washington, D. C.

[28] Borror, D. J., Delong D. M., \& Triplehorn C. A., 1981. An Introduction to the Study of Insects, $5^{\text {th }}$ ed. Saunders College Publications, Philadelphia.

[29] Delvare, G., \& Aberlanc, H. P., 1989. Les insects d'Afrique et d'Amérique tropicale. Clés pour la reconnaissance des familles. PRIFAS, CIRADGERDAT, Montpellier, France, 302 pp.

[30] Santosh, P., \& Prem, B. B., 2014. Key to identify insects from droppings of some Insectivorous bats of Nepal. Journal of Institute of Science and Technology, 19 (1); 129-136.

[31] Ponmalor, S., \& Vanitharani, J., 2014. Insect pest management by horse shoe bats (Rhinolophus species) in the forest ecosystem of Kalakad Mundanthurai Tiger Reserve India. Scrutiny International Research Journal of Biological and environmental Science. 1: 5 2348-578.

[32] Hammer, ø., Harper, D. A. T., \& Ryan, P. D., 2001. Past: Paleontological Statistics Software Package for Education and Data Analysis. Paleontologia Electronica 4 (1); 9pp.

[33] Aldridge, H. D. J., Rautenbach I. L., 1987. Morphology, echolocation and resource partitioning in insectivorous bats. Journal of Animal Ecology 56: 763-778.

[34] Siemers, M. B., and R., Güttinger. (2006). Prey conspicuousness can explain apparent prey selectivity. Current Biology, 16: 157-159.

[35] Whitaker, J. O. Jr., \& Yom-Tov Y., 2002. The Diet of some Insectivorous bats from northern Israel. Mamm. biol. 67: 378380 .

[36] Bogdanowicz, W. Fenton, M. B., \& Daleszczyk K., 1999 The relationships between echolocation calls, morphology and diet in insectivorous bats. Journal of Zoology, 247: 381-393.
[37] Weterings, R., \& Umponstira, C., 2014. Bodyweight-forearm ratio, cranial morphology and call frequency relate to prey selection in insectivorous bats. Electronic Journal of Biology, 10: 21-27.

[38] Whitaker, J. O. Jr., Neefus, C., \& Kunz, T. H., 1996. Dietary Variation in the Mexican Free-tailed Bat (Tadarida brasiliensis mexicana). J. Mammal., 77 (3); 716-724.

[39] Lee, Y., Mccracken, G. F., 2005. Dietary variation of Brazilian free-tailed bats links to migratory populations of pest insects. Journal of Mammalogy, 86: 67-76.

[40] Naidoo, S., Mackey, R. L., \& Schoeman, M. C., 2011. Foraging ecology of insectivorous bats at a polluted and an unpolluted river in an urban landscape. Durban Museum Novitates 34: 21-28.

[41] Fenton, M. B., Cumming, D. H. M., Rautenbach, I. L., Cumming, G. S., Cumming, L. S., Ford, G., Taylor, D. R., Dunlop, J., Hovorka, M. D., Johnston, D. S., Portfors, C. V., Kalcounis, M. C., \& Mhlanga, Z., 1998. Bats and the loss of tree canopy in African woodlands. Conserv. Biol. 12. 399-407.

[42] Taylor, P. J., 2000. Bats of southern Africa. University of Natal Press: Pietermaritzburg, pp. 206.

[43] Macarthur, R. H., \& Pianka, E. R., 1966. On optimal use of apatchy environment. The American Naturalist 100: 603-609.

[44] Jones, G., 1990. Prey selection by the greater horseshoe bat (Rhinolophus ferrumequinum); optimal foraging by echolocation? Journal of Animal Ecology, 59 (2); 587-602.

[45] Beck A., 1995. Fecal analyses of European bat species. Myotis 32-33: 109-119.

[46] Rydell, J., \& Petersons. G., 1998. The diet of the noctule bat Nyctalus noctula in Latvia. Z. Säugetierkd, 63: 79-83.

[47] Feldman, R., Whitaker, J. O., Yom-Tov, Y., 2000. Dietary composition and habitat use in a desert insectivorous bat community in Israel. Acta chiro. 2, 15-22.

[48] Barlow, K., 1997. The diets of two phonic types of the bat Pipistrellus pipistrellus in Britain. J. Zool. Lond. 243: 597609.

[49] Bartonička, T., Řehak, Z., \& Andreas, M., 2008. Diet composition and foraging activity of Pipistrellus pygmaeus in a floodplain forest. Biologia 63/2: 1-7.

[50] Kurta, A., \& Whitaker, J. O., 1998. Diet of Endangered Indiana bat, Myotis sodalist on the northern edge of its range. Am. Midl. Nat. 140: 280-286.

[51] Leelapaibul, W., Bumrungsri, S., \& Pattanawiboon, A., 2005 Diet of wrinkle-lipped free-tailed bat (Tadarida plicata Buchannan, 1800) in central Thailand: insectivorous bats potentially act as biological pest control agents. Acta Chiropterologica, 7: 111-119.

[52] Zhang, L., Jones, G., Rossiter, S., Ades, G., Liang, B., \& Zhang, S., 2005 Diet of flat-headed bats, Tylonycteris pachypus and T. robustula, in Guangxi, south China. Journal of Mammalogy, 86: 61-6.

[53] Monadjem, A., Taylor. P. J., Cotterill. F. P. D. \& Schoeman, M. C., 2010. Bats of Southernand Central Africa: A Biogeographic and Taxonomic Synthesis. University of Witwatersrand Press, Johannesburg. 